\title{
Adsorptive removal of reactive dyes from aqueous solution using activated carbon synthesized from waste biomass materials
}

\author{
P. V. Thitame ${ }^{1} \cdot$ S. R. Shukla ${ }^{1}$
}

Received: 28 August 2014/Revised: 16 July 2015/Accepted: 29 September 2015/Published online: 14 October 2015

(C) Islamic Azad University (IAU) 2015

\begin{abstract}
High-activity mesoporous carbons were prepared from wild almond shells and coir pith by phosphoric acid activation and applied for adsorption of the dyes, C.I. Reactive Red 2 and C.I. Reactive Yellow 145A. The BET surface areas of these activated carbons were found to be 1133.25 and $1210.58 \mathrm{~m}^{2} / \mathrm{g}$, respectively. The equilibrium data were best described by the Langmuir isotherm in all the cases. The maximum dye adsorption capacity shown by the activated carbon produced from coir pith was $2022.9 \mathrm{mg} / \mathrm{g}$ for C.I. Reactive Red 2 and $1694.3 \mathrm{mg} / \mathrm{g}$ for C.I. Reactive Yellow $145 \mathrm{~A}$ at $60{ }^{\circ} \mathrm{C}$ with initial concentration of $1000 \mathrm{mg} / \mathrm{L}$. Pseudo-second-order kinetic model gave a good fit, with the intraparticle diffusion being one of the essential rate-controlling steps. Thermodynamic analysis revealed that the adsorption of both the dyes on activated carbons was spontaneous and endothermic in nature. The $t$ test analysis showed that the difference between adsorption capacities of the produced activated carbons was not significant at $95 \%$ confidence level at all the temperatures studied.
\end{abstract}

Keywords Adsorption kinetics · Coir pith · Phosphoric acid activation - Wastewater $\cdot$ Wild almond shell

Electronic supplementary material The online version of this article (doi:10.1007/s13762-015-0901-3) contains supplementary material, which is available to authorized users.

S. R. Shukla

srshukla19@gmail.com

1 Department of Fibres and Textile Processing Technology, Institute of Chemical Technology (University under Section3 of UGC act 1956), Nathalal Parekh Marg, Matunga, Mumbai 400 019, India

\section{Introduction}

Activated carbon (AC) is produced by the incomplete combustion of carbonaceous material and possesses high surface area in the range of $500-1500 \mathrm{~m}^{2} / \mathrm{g}$. It is one of the most important and popular commercial adsorbents. The adsorption characteristics and the porosity development of $\mathrm{AC}$ depend on the type and properties of the precursor and also on the activation method (Bansal et al. 1999; Girgis and Hendawy 2002). Several precursors have been used for the production of AC such as corn cob (Tsai et al. 1997), coconut shell (Hu and Srinivasan 1999), palm shell (Daud et al. 2000), apple pulp (Suarez et al. 2002), sawdust and rice husk (Malik 2003), jute fiber (Senthilkumaar et al. 2005), fluted pumpkin seed shell (Okoye et al. 2010). The selection of the precursor depends on its cost, availability and carbon content.

Activation methods are broadly classified into physical and chemical methods. Chemical activation has many advantages over the physical activation such as high yield, activation at lower temperatures and better development of porosity (Ramakrishnan and Namasivayam 2009; Sugumaran et al. 2012) leading to high surface area. The commonly used chemical activating agents are $\mathrm{H}_{3} \mathrm{PO}_{4}, \mathrm{KOH}$ and $\mathrm{ZnCl}_{2}$. Phosphoric acid $\left(\mathrm{H}_{3} \mathrm{PO}_{4}\right)$ as a chemical activating agent has become popular since it is environment friendly and can be easily removed during washing of AC (Reddy et al. 2015). One-step chemical activation is distinctly different from two-step activation since it requires single heat treatment, wherein the carbonization and activation occur simultaneously. Physicochemical activation, which consists of chemical treatment of the precursor followed by the physical activation, giving synergistic effect, is also reported (Idris et al. 2011). 
Highly purified ACs have widespread applications in pharmaceutical, food and medical field for the binding of toxins and gases. Wastewater reclamation is another important application in which the dissolved organic toxic pollutants like phenols and their derivatives ( $\mathrm{La}$ and Szu 2001), dyes (Malik 2003) and heavy metals (Kermit et al. 2006) are removed. Synthetic dyes are used in textile, paper, rubber, plastic and cosmetic industries. Among them, the reactive dyes are widely used for the dyeing of cellulosic textiles due to their excellent fastness properties coupled with full color gamut. However, all the dye cannot be taken up by the textile material and the unfixed dye eventually goes into the wastewater after washing. Accordingly, up to $50 \%$ reactive dye is present in the wastewater depending upon the degree of fixation (Al-Degs et al. 2008). Also, a part of reactive dye is hydrolyzed due to the alkali used in the dye bath which is unable to be fixed onto the cotton textile. Removal of dyes from wastewater is important because they are recalcitrant and hinder photosynthesis of aquatic plants and some of them are also toxic, carcinogenic and/or mutagenic (Allegre et al. 2006; Cardoso et al. 2011).

Wild almond shells (sterculia foetida) and coir pith both are the typical lignocellulosic carbonaceous materials, suitable for the production of AC. These can be used as cheap and renewable starting materials for the same instead of fossil fuels. This study aims to develop highsurface-area ACs from these precursor materials using one-step chemical activation. The produced ACs were then applied for the adsorptive removal of two extensively used reactive dyes from their aqueous solutions. This study was carried out from August 2013 to March 2014 at Institute of Chemical Technology (ICT), Matunga, Mumbai, India.

\section{Materials and methods}

Wild almond shells were collected from the surrounding area of ICT campus, and the coir pith was procured locally. Wild almond shells were cut into small pieces first and then ground to fine powder. Coir pith was used as obtained. Both the precursor materials were washed thoroughly with water to remove the dirt and dust present and then oven-dried at $105{ }^{\circ} \mathrm{C}$ overnight. All the chemicals used, viz phosphoric acid, hydrochloric acid and sodium hydroxide, were of laboratory grade and were procured from S D Fine-Chem Limited, India. Both the dyes C.I. Reactive Red 2 (RR 2) and C.I. Reactive Yellow 145A (RY 145A) were procured from Atul, India.

\section{Synthesis of AC}

Ten gram samples each of wild almond shells (AS) and coir pith (CP) were treated with phosphoric acid of 68 and $75 \% \mathrm{w} / \mathrm{w}$ concentration at boil with impregnation ratios of 5.53 and 8.65 , respectively. The impregnation ratio $(X p)$ is defined as the ratio of mass of an activating agent to the mass of the precursor. The impregnated mass was then left soaking for $24 \mathrm{~h}$ at room temperature. It was then filtered and oven-dried at $105{ }^{\circ} \mathrm{C}$ overnight.

The soaked precursors were subjected to carbonization in a muffle furnace under nitrogen atmosphere with conditions, $700{ }^{\circ} \mathrm{C}, 1 \mathrm{~h}$ for activated carbon from wild almond shells (AC-AS) and $600{ }^{\circ} \mathrm{C}, 2 \mathrm{~h}$ for activated carbon from coir pith (AC-CP). The trial experiments showed that these conditions give best ACs in terms of surface area and yield. Online Resource 1 shows the optimization of process parameters for both ACs. The produced ACs were cooled in a dessicator and then treated with $0.5 \mathrm{~N} \mathrm{NaOH}$ to neutralize the residual acid. It was further treated with $0.1 \mathrm{~N}$ $\mathrm{HCl}$ and washed extensively with distilled water till $\mathrm{pH}$ of the washing effluent becomes neutral. The samples were then oven-dried at $110{ }^{\circ} \mathrm{C}$ for $4 \mathrm{~h}$. Grinding of the ACs was done manually using mortar and pestle.

\section{Characterization of $\mathrm{AC}$}

Methylene blue (MB) value of $\mathrm{AC}$ indicates the maximum volume of standard MB solution $(0.15 \%)$ decolorized by a fixed amount of AC. Carefully weighed $0.1 \mathrm{~g}$ AC was added to a flask containing $5 \mathrm{~mL}$ of standard $\mathrm{MB}$ solution $(0.15 \%)$ and shaken to decolorize. Definite volume $(1 \mathrm{~mL})$ of MB solution was added subsequently to the flask till complete decolorization occurred within $5 \mathrm{~min}$. The entire volume of MB added was noted, and the MB value is reported in $\mathrm{mg} / \mathrm{g}$.

The $\mathrm{pH}$ of zero point of charge $\left(\mathrm{pH}_{z p c}\right)$ of $\mathrm{AC}$ was determined by the $\mathrm{pH}$ drift method (Yennam et al. 2014). $\mathrm{CaCl}_{2}$ solution $(0.005 \mathrm{M})$ was boiled to remove $\mathrm{CO}_{2}$ and cooled. The initial $\mathrm{pH}$ was adjusted between 2 and 12 for each $20 \mathrm{~mL}$ of the above-mentioned solution using $0.5 \mathrm{M}$ $\mathrm{HCl} / \mathrm{NaOH}$. AC (0.06 g) was added, and the solutions were equilibrated for $24 \mathrm{~h}$. Final $\mathrm{pH}$ was measured and plotted against the corresponding initial $\mathrm{pH}$. The point where this curve intersects the straight line passing through origin indicates $\mathrm{pH}_{z p c}$.

The mean particle size of AC was obtained from CILAS 1064 Particle size analyzer, France. Carbon suspension was made using $0.2 \mathrm{~g} \mathrm{AC}$ and diluted to appropriate volume. With constant stirring, particle size analysis was done based on the laser diffraction principle. 
BET surface area analysis was done using Micromeritics ASAP-2020 instrument, USA. AC samples were first degassed under high vacuum at $350{ }^{\circ} \mathrm{C}$ for $8 \mathrm{~h}$. Nitrogen adsorption-desorption isotherms of ACs were measured at liquid nitrogen temperature $(77 \mathrm{~K})$. By the analysis of $\mathrm{N}_{2}$ adsorption-desorption isotherm profile, the BET surface area, micropore volume and the total pore volume were obtained. The mesoporous volume was obtained by subtracting the microporous volume from the total pore volume.

Scanning electron microscopy (SEM) was done using JEOL JSM-6380LA, Japan, operated at $20 \mathrm{kV}$ to characterize the surface morphology of the carbon samples. Samples were degassed under vacuum prior to analysis and then mounted on adhesive carbon tape attached to an aluminum stub. Samples were subsequently coated with platinum using sputter coater. The SEM images were taken at $500 \times$ and $1000 \times$ magnifications.

\section{Dye adsorption studies}

Stock solutions of the two reactive dyes $(1 \mathrm{~g} / \mathrm{L})$ were prepared, and the range of required concentrations was made by dilutions with distilled water. The initial $\mathrm{pH}$ was adjusted using $\mathrm{H}_{2} \mathrm{SO}_{4}(1 \mathrm{~N})$ and $\mathrm{NaOH}(1 \mathrm{~N})$ solutions. Stoppered Erlenmeyer flasks containing $50 \mathrm{~mL}$ dye solution and AC dosage $(0.3 \mathrm{~g} / \mathrm{L})$ were agitated for $4 \mathrm{~h}$ at $60 \mathrm{rpm}$, assuming that the equilibrium has reached. The decolorized samples were filtered out, and the residual dye concentration was analyzed using UV-Visible spectrophotometer, 8500 TECHCOMP, Hong Kong. The absorbance was read at 535 and $420 \mathrm{~nm}$ for RR 2 and RY $145 \mathrm{~A}$, respectively.

The effect of initial solution $\mathrm{pH}$ on the dye adsorption by ACs was studied at a concentration of $400 \mathrm{mg} / \mathrm{L}$. The initial $\mathrm{pH}$ was varied from 1.0 to 7.0 to see the effect of $\mathrm{pH}$. For adsorption isotherm studies, the effect of initial dye concentration (250-1000 mg/L) was seen on the equilibrium dye adsorption on $\mathrm{ACs}$ at $30^{\circ} \mathrm{C}$. The isotherm study was repeated at 45 and $60{ }^{\circ} \mathrm{C}$, to determine the effect of temperature on the dye adsorption by ACs. The thermodynamic parameters obtained at these temperatures were then compared. All the isotherm experiments were carried out in triplicate, and the average values have been reported. Adsorption studies were carried out for $8 \mathrm{~h}$ to determine the effect of time on the adsorption at initial dye concentration of $800 \mathrm{mg} / \mathrm{L}$. The volume of the dye solutions was kept $150 \mathrm{~mL}$, so that the samples were withdrawn after a fixed time period for the analysis. The dye adsorptions at equilibrium and at time ' $t$ ' were calculated using the formulae $\left(C_{0}-C_{\mathrm{eq}}\right) * 3.33$ and $\left(C_{0}-C_{t}\right) * 3.33$, respectively.

\section{Adsorption isotherms}

The equilibrium data of the ACs were analyzed using the Langmuir, Freundlich, Temkin and Dubinin-Radushkevich (D-R) isotherms, which are the widely used two-parameter models. The Langmuir isotherm is valid for monolayer adsorption onto a homogeneous adsorbent surface, with no or negligible interaction (Vargas et al. 2011). It assumes adsorbent with a finite number of identical adsorption sites. The linearized form of the Langmuir equation is

$\frac{C_{\mathrm{eq}}}{q_{\mathrm{eq}}}=\frac{C_{\mathrm{eq}}}{Q^{\circ}}+\frac{1}{b Q^{\circ}}$

where $Q^{\circ}$ and $b$ are the Langmuir constants related to the maximum monolayer adsorption capacity and bonding energy, respectively.

The characteristic feature of the Langmuir isotherm is the dimensionless separation factor given by,

$R_{L}=\frac{1}{1+b C_{0}}$

The value of $R_{L}$ indicates the favorability of adsorption; it is unfavorable if $R_{L}>1$, linear if $R_{L}=1$, favorable if $0<R_{L}<1$ or irreversible if $R_{L}=0$.

The Freundlich, Temkin and D-R isotherms are presented in Online Resource 1.

\section{Adsorption kinetics}

Simple kinetic models were applied to analyze the kinetic data of RR 2 and RY 145A. The linearized form of the Lagergren first-order equation is given by,

$\log \left(q_{\mathrm{eq}}-q_{t}\right)=\log q_{\mathrm{eq}}-\frac{k_{1}}{2.303} t$

where $k_{1}$ is the first-order rate constant of adsorption. Generally, first-order model is applicable only to the initial period, where the dye adsorption increases linearly with time.

The linear form of pseudo-second-order kinetic model is given by,

$\frac{t}{q_{t}}=\frac{1}{k_{2} q_{\mathrm{eq}}^{2}}+\frac{t}{q_{\mathrm{eq}}}$

where $k_{2}$ is the second-order rate constant of adsorption. A straight line of $t / q_{t}$ versus $t$ gives applicability of this model, and $q_{\text {eq }}$ and $k_{2}$ were determined from the slope and intercept of the plot.

The linear form of the intraparticle diffusion model (Weber and Morris 1963) is given by the equation,

$q_{t}=k_{\mathrm{id}} \sqrt{t}+I$

where $k_{\mathrm{id}}$ is the intraparticle diffusion rate and $I$ gives the approximate value of boundary layer thickness. According 
to this model, amount of dye adsorbed varies proportionately with square root of time. If a straight line of $q_{t}$ versus $\sqrt{ } t$ passes through the origin, then intraparticle diffusion is the sole rate-controlling step. The validity of the models can be checked from the linear plots (not shown) and by comparing the correlation coefficients $\left(R^{2}\right)$.

\section{Adsorption thermodynamics}

The relation between the adsorption equilibrium constant $k_{L}$, obtained from the Langmuir isotherm, and the temperature is given by the van't Hoff equation (Namasivayam and Kavitha 2002),

$\ln k_{L}=\frac{\Delta S^{\circ}}{R}-\frac{\Delta H^{\circ}}{R T}$

where $R$ is the universal gas constant and $T$ is the absolute temperature. The enthalpy $\left(\Delta \mathrm{H}^{\circ}\right)$ and the entropy $\left(\Delta \mathrm{S}^{\circ}\right)$ changes of the adsorption were determined from the van't Hoff plot (not shown), and the Gibb's free energy $\left(\Delta \mathrm{G}^{\circ}\right)$ of the adsorption at different temperatures was determined from the relation,

$\Delta G^{\circ}=\Delta H^{\circ}-T \Delta S^{\circ}$

All the experiments were carried out in duplicate, and the average values have been reported.

\section{Significance testing}

The significance testing was done using student's $t$ test analysis by comparing the mean values of the adsorption isotherm data of AC-AS and AC-CP, obtained at all the temperatures studied.

\section{Results and discussion}

\section{Characterization of $\mathrm{AC}$}

MB value indicates mainly meso- and macropore content, often termed as the decolorizing power of AC. For AC-AS and AC-CP, it was found to be 270 and $300 \mathrm{mg} / \mathrm{g}$, respectively. The $\mathrm{pH}_{z p c}$ of $\mathrm{AC}$ is very useful in the liquidphase adsorption applications, since it gives the working $\mathrm{pH}$ range of $\mathrm{AC}$ depending on the ionic nature of the adsorbate. The $\mathrm{pH}_{z p c}$ of AC-AS and AC-CP was 7.4 and 6.5 , respectively. The size of powdered $\mathrm{AC}$ (PAC) is $<180 \mu$. The smaller the size of $\mathrm{AC}$, the faster is the kinetics, and the resistance to diffusion is also reduced. The mean particle size of both AC-AS and AC-CP was around $50 \mu$.

The BET analysis showed that both the ACs were predominantly mesoporous in nature. The average pore width was in the range $3-5 \mathrm{~nm}$. This is due to the high phosphoric acid impregnation ratios used which causes expansion of the pores (Reffasa et al. 2010). AC-AS has less surface area $\left(1133.25 \mathrm{~m}^{2} / \mathrm{g}\right)$ as compared to AC-CP $\left(1210.58 \mathrm{~m}^{2} / \mathrm{g}\right)$, which has high micropore volume. The total pore volumes of AC-AS and AC-CP were 1.41 and $1.14 \mathrm{~cm}^{3} / \mathrm{g}$, respectively.

Figure 1 shows the SEM images of AC-AS and AC-CP, in which the pores formed have been clearly marked. The surface topologies differed due to two different raw materials used as precursor for AC production. Unlike ACAS, the high concentration and amount of phosphoric acid resulted in the expanded pore structure to be developed in AC-CP.

\section{Dye adsorption studies}

\section{Effect of solution $\mathrm{pH}$}

The adsorption of the dyes on AC is largely affected by the solution $\mathrm{pH}$ (Cardoso et al. 2011). Figure 2 shows the effect of initial solution $\mathrm{pH}$ on the dye adsorption at an initial concentration of $400 \mathrm{mg} / \mathrm{L}$. The optimum solution

(a)

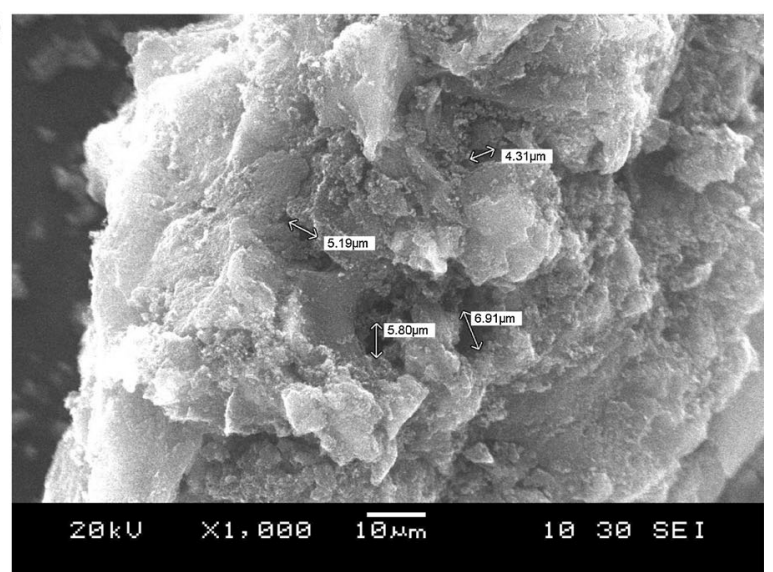

(b)

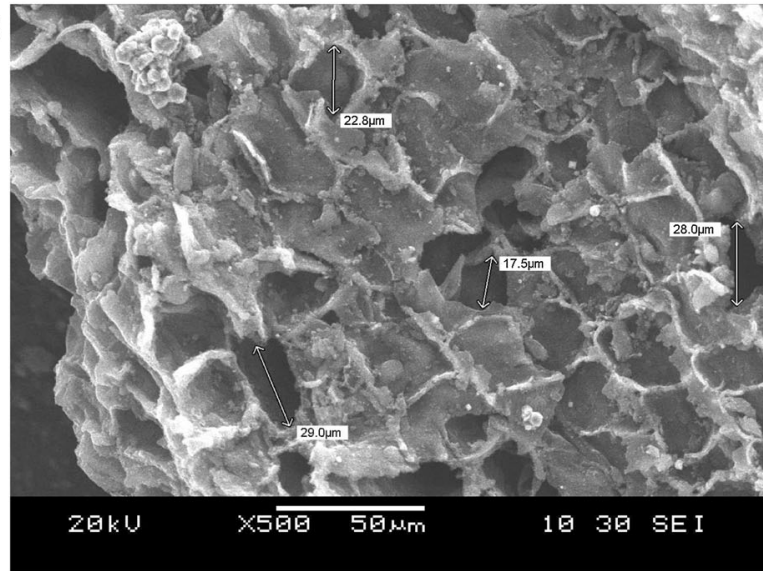

Fig. 1 SEM images of a AC-AS and b AC-CP 


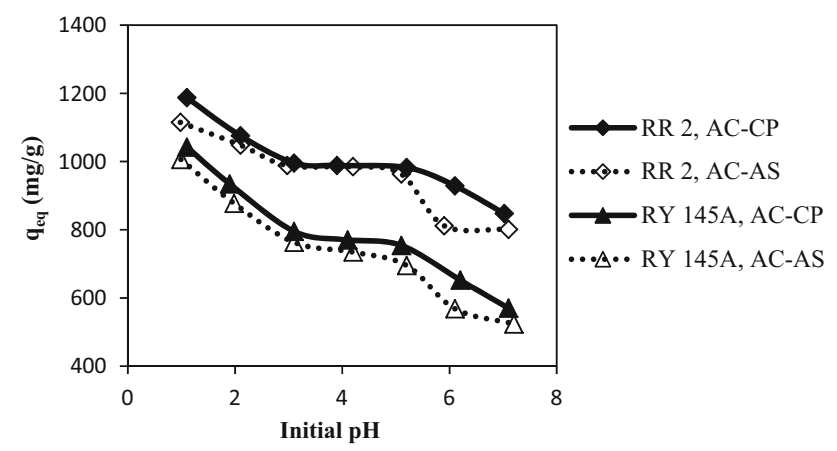

Fig. 2 Effect of solution $\mathrm{pH}$ on the equilibrium dye adsorption on AC-AS and AC-CP $\left(C_{0}: 400 \mathrm{mg} / \mathrm{L}, \mathrm{AC}: 0.3 \mathrm{~g} / \mathrm{L}, T: 30^{\circ} \mathrm{C}, t: 4 \mathrm{~h}\right)$

$\mathrm{pH}$ was found to be 1.0 in all the cases, the dye adsorption values being 1114.9 and $1187.4 \mathrm{mg} / \mathrm{g}$ for C.I. Reactive Red 2 (RR 2) on AC-AS and AC-CP, respectively. Little less adsorption (1006.3 and $1042.4 \mathrm{mg} / \mathrm{g}$ ) of C.I. Reactive Yellow 145A (RY 145A) is attributed to its larger molecular size. The final $\mathrm{pH}$ after adsorption showed insignificant variation, thereby supporting that no ion exchange mechanism is involved. The physical forces like van der Waal's, hydrogen bonding, dipole-dipole interactions may contribute to this higher adsorption (Al-Degs et al. 2008). Similar results are reported for the adsorption of reactive dyes onto ACs prepared from coconut tree flower, jute fiber and sugarcane bagasse pith (Senthilkumaar et al. 2006; Amin 2008).

\section{Adsorption isotherm}

Figure 3 shows the observed adsorption isotherms at $30{ }^{\circ} \mathrm{C}$ with the fitted model isotherms, except for D-R isotherm which gave a poor fit. Similar isotherm curves were obtained at 45 and $60{ }^{\circ} \mathrm{C}$ (not shown). The equilibrium dye adsorption increased with the increasing initial dye concentration, since it is the main driving force to overcome the mass transfer resistance (Mahmoud et al. 2012). The high adsorption capacity of AC-AS and AC-CP for both the dyes is due to the high surface area and the mesoporous nature of both the carbons. Table S1 (Online Resource 1) compares the adsorption capacities of various ACs for the reactive dyes. It is clear that the adsorption capacities of AC-AS and $\mathrm{AC}-\mathrm{CP}$ are very high, as compared to other ACs. The isotherms were concave to the horizontal axis, indicating high adsorption affinity of both ACs for the dyes. The experimental data and the calculated values from the models yielded the typical type I isotherms according to IUPAC, indicating monolayer adsorption onto microporous adsorbents.

Fig. 3 Adsorption isotherms of RR 2 and RY 145A on AC-AS and AC-CP (solution pH: 1.0, AC: $0.3 \mathrm{~g} / \mathrm{L}, T: 30{ }^{\circ} \mathrm{C}, t: 4 \mathrm{~h}$ )
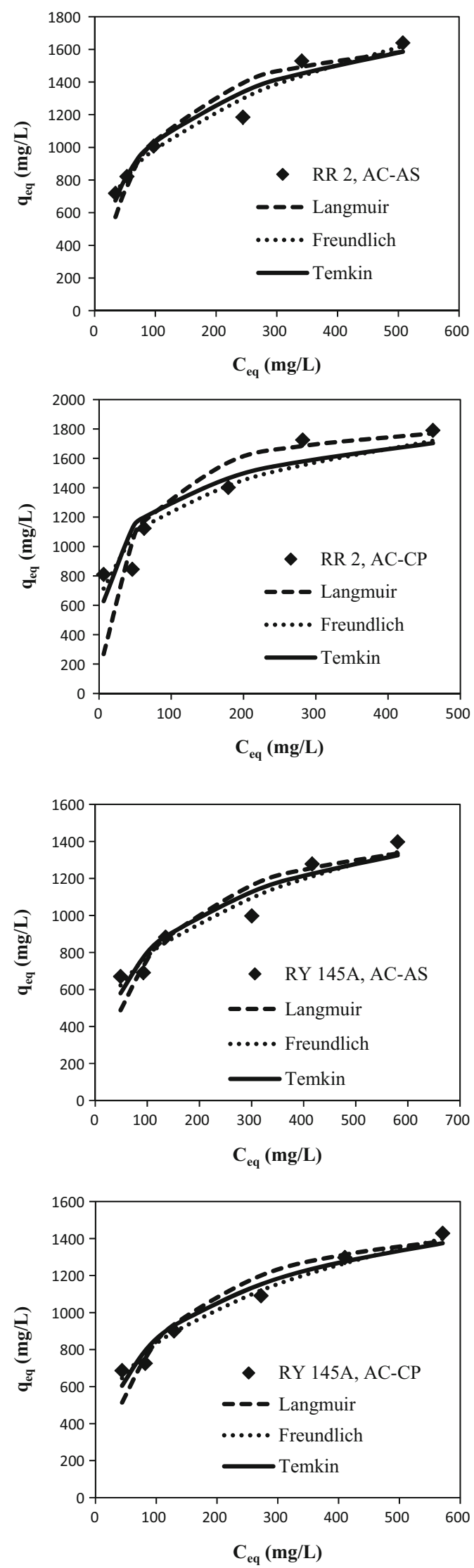
Table 1 Isotherm parameters of adsorption by AC-AS and AC-CP

\begin{tabular}{|c|c|c|c|c|c|c|c|c|c|}
\hline \multirow[t]{2}{*}{ Dye } & \multirow[t]{2}{*}{ Adsorbent } & \multirow[t]{2}{*}{$q_{\text {eq, exp }}(\mathrm{mg} / \mathrm{g})$} & \multicolumn{4}{|c|}{ Langmuir model } & \multicolumn{3}{|c|}{ Temkin model } \\
\hline & & & $R^{2}$ & $Q^{\circ}(\mathrm{mg} / \mathrm{g})$ & $R_{L}$ & $b(\mathrm{~L} / \mathrm{mg})$ & $R^{2}$ & $B_{t}(\mathrm{~J} / \mathrm{mol} / \mathrm{K})$ & $A_{t}(\mathrm{~L} / \mathrm{g})$ \\
\hline \multirow[t]{2}{*}{ RR 2} & AC-AS & 1639.9 & 0.98 & 1818.18 & 0.069 & 0.013 & 0.84 & 7.45 & 0.22 \\
\hline & $\mathrm{AC}-\mathrm{CP}$ & 1791.2 & 0.99 & 1923.08 & 0.039 & 0.025 & 0.95 & 9.99 & 1.87 \\
\hline \multirow[t]{2}{*}{ RY 145A } & AC-AS & 1397.4 & 0.96 & 1587.30 & 0.098 & 0.009 & 0.96 & 8.38 & 0.14 \\
\hline & AC-CP & 1428.4 & 0.99 & 1612.90 & 0.086 & 0.011 & 0.91 & 8.39 & 0.17 \\
\hline
\end{tabular}

Table 1 shows the parameters of the Langmuir and the Temkin isotherms of RR 2 and RY $145 \mathrm{~A}$ at $30^{\circ} \mathrm{C}$. The applicability of the models was in the following order: Langmuir $>$ Temkin $>$ Freundlich $>$ D-R, in terms of $\mathrm{R}^{2}$. The parameters of Freundlich and D-R isotherms are presented in Table S2, Online Resource 1. The Langmuir model was the best fit, with high values of $R^{2}$, nearing to 1 . High values of $Q^{\circ}$ for AC-CP are due to its larger surface area. The value of $b$ is related to the free energy of adsorption and indicates the affinity for the dye adsorption. The high values of $b$ indicates strong bonding of the dyes onto ACs. The values of $R_{L}$ between 0 and 1 in all the cases indicate favorable adsorption of both the dyes by the ACs produced. The values of $n$ obtained from Freundlich isotherm were above unity for both the dyes, indicating favorable physical adsorption (Kumar et al. 2010). The parameter $1 / n$ expresses heterogeneity of the carbon surface which increases as the value of $1 / n$ gets closer to zero. The very low values of $1 / n$ ranging from 0.2 to 0.3 indicate the heterogeneous nature of both the ACs. However, Langmuir isotherm is valid for only homogeneous adsorbents and gives no information on the multilevel adsorption. Since AC is highly heterogeneous having many pores, multilayer adsorption may be possible due to physical interactions. Similar results are reported for the heterogeneous ACs where the Langmuir isotherm fitted the equilibrium data well (Auta and Hameed 2011; Ghaedi et al. 2013). The positive values of $B_{t}$ obtained from the Temkin isotherm confirmed the endothermic nature of the dye adsorption. The values of $E$ obtained from the D-R isotherm between 5-7 $\mathrm{kJ} / \mathrm{mol}$ and indicate that the adsorption of both the dyes onto AC-AS and AC-CP was physical (Ahmad et al. 2014).

\section{Adsorption kinetics}

Figure 4 shows the adsorption kinetics of RR 2 and RY $145 \mathrm{~A}$ at $60^{\circ} \mathrm{C}$ on $\mathrm{AC}-\mathrm{AS}$ and $\mathrm{AC}-\mathrm{CP}$. At a given dye concentration, the dye adsorption by both the ACs initially increased rapidly and linearly up to $200 \mathrm{~min}$ and thereafter slowly. The majority of the dye adsorption (50-75\%) occurred within the first $1 \mathrm{~h}$, and such a rapid removal indicates physisorption of the dyes.

From the kinetic parameters, given in Table 2, it is clear that pseudo-second-order model is applicable with high correlation coefficients. The parameters of pseudo-firstorder model are not shown since it gave a poor fit. It is well known that the adsorption takes place in three steps: external mass transfer or the film diffusion, intraparticle diffusion and the final adsorption on to a site. The adsorption performance of $\mathrm{AC}$ depends on the surface area and the porosity (Al-Degs et al. 2004). For the transfer of dye molecules from the aqueous phase onto AC surface, high surface area is important. As the mass transfer resistance reduces with increasing dye concentration, dye molecules diffuse through the pores of AC. Applicability of pseudo-second-order model indicates chemisorption with the intraparticle diffusion as one of the essential rate-controlling steps. However, isotherm studies reveal that the adsorption was physical in nature. Similar results are reported in the literature where the adsorption of dyes was physical and followed second-order kinetics (Ahmad et al. 2014; Ghaedi et al. 2013). To confirm that the intraparticle diffusion is the only rate-controlling step, the kinetic data also need to be tested by the intraparticle diffusion and the saturation type model, which will give information on the final adsorption step (Aksu and Isoglu 2006).

Figure S2 (Online Resource 1) shows the intraparticle diffusion plot of RR 2 and RY 145A. The typical multilinear profile of the curves shows that the adsorption process followed three steps mentioned above. The initial sharp increase in the dye uptake is due to the external mass transfer, the middle linear portion of the curve indicating gradual increase in the dye adsorption is due to the intraparticle diffusion, and the final portion of the curve is attributed to the adsorption step. The linear plots of $q_{t}$ versus $\sqrt{ } t$ (not shown) did not pass through the origin, confirming that the intraparticle diffusion was not the only 

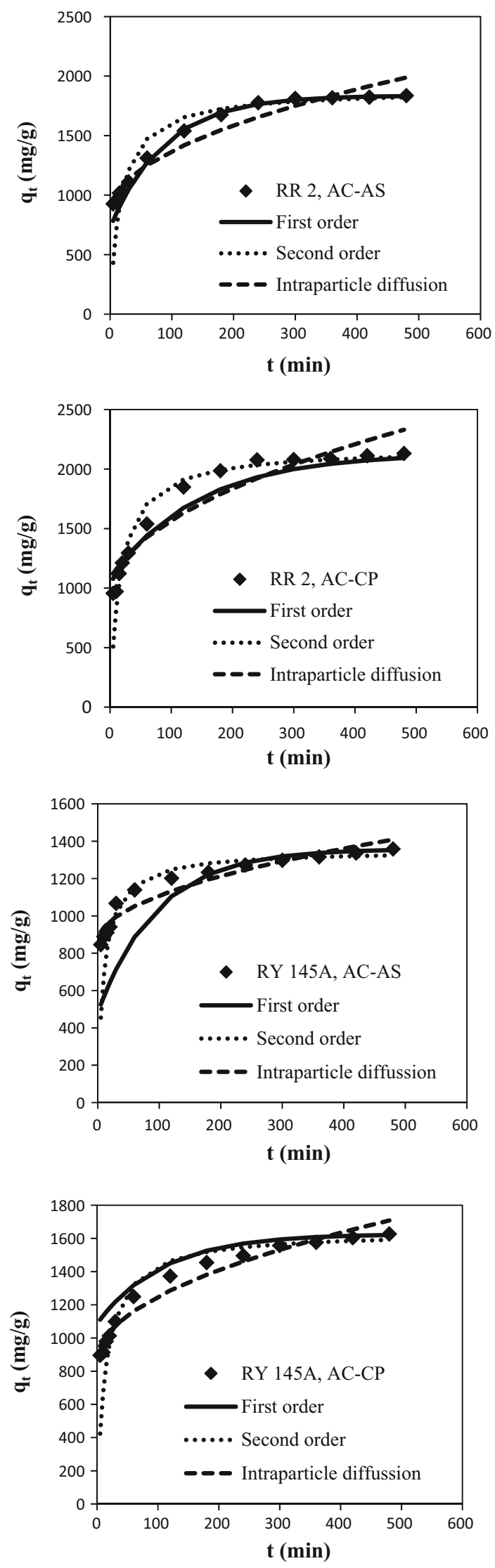

4Fig. 4 Adsorption kinetics of RR 2 and RY 145A on AC-AS and AC-CP $\left(C_{0}: 800 \mathrm{mg} / \mathrm{L}\right.$, solution $\mathrm{pH}: 1.0$, AC: $\left.0.3 \mathrm{~g} / \mathrm{L}, T: 60{ }^{\circ} \mathrm{C}\right)$

rate-limiting step (Wu et al. 2001). The high values of I (Table 2) showed the significant contribution of the external mass transfer onto carbon surfaces. It is known that the final adsorption is generally faster and does not affect the adsorption rate greatly. Therefore, it can be concluded that the adsorption of RR 2 and RY 145A onto ACs was controlled by the external mass transfer and the intraparticle diffusion.

\section{Adsorption thermodynamics}

The thermodynamic parameters give idea about the feasibility and spontaneity of the reaction and also some information on the adsorption mechanism or the interaction. The thermodynamic parameters studied at different temperatures are presented in Table 3 . The adsorption capacity of AC-AS and AC-CP was affected by the temperature in a positive manner. When the temperature was increased from 30 to $60{ }^{\circ} \mathrm{C}$, the adsorption capacity of AC-CP increased from 1791.2 to $2022.9 \mathrm{mg} / \mathrm{g}$ for RR 2 and from 1428.4 to $1694.3 \mathrm{mg} / \mathrm{g}$ for RY $145 \mathrm{~A}$. This can be attributed to the activation of the sorbent surface at high temperature and the adsorption into the micropores, due to increased diffusion rate (Ahmad et al. 2014). The positive values of $\Delta \mathrm{H}^{\circ}$ confirmed that the adsorption of both the dyes onto ACs was endothermic. The negative values of $\Delta \mathrm{G}^{\circ}$ confirmed the feasibility and spontaneity of the reaction which increased with temperature, while positive values of $\Delta \mathrm{S}^{\circ}$ confirmed the increased randomness of the adsorption at solid-liquid interface. The negative values of $\Delta G^{\circ}$ were between 6 and $12 \mathrm{~kJ} / \mathrm{mol}$, indicating that the physical forces like van der Waal's, hydrogen bonding and dipole-dipole interactions may be involved in the adsorption (Huang et al. 2007). Some oxygen-containing functional groups like hydroxyl, carboxyl and carbonyl present on the $\mathrm{AC}$ are able to interact chemically with the dye molecules (Al-Degs et al. 2000), but in the present case, it seems that such interactions may be almost negligible when compared to the impact of high surface areas of the ACs.

\section{Significance testing}

The isotherm data of RR 2 and RY 145A on AC-AS and AC-CP were compared using the $t$ test analysis, at all the temperatures studied. The experimental $t$ values were quite low (0.2-0.5) as compared to the standard value (2.2), indicating that there is not much difference between the adsorption capacities of AC-AS and of AC-CP. Also, as expected, the $t$ values were lower at higher temperature and 
Table 2 Adsorption kinetic parameters of RR 2 and RY 145A on AC-AS and AC-CP

\begin{tabular}{|c|c|c|c|c|c|c|c|c|}
\hline \multirow[t]{2}{*}{ Dye } & \multirow[t]{2}{*}{ Adsorbent } & \multirow[t]{2}{*}{$q_{\text {eq, exp }}(\mathrm{mg} / \mathrm{g})$} & \multicolumn{3}{|c|}{ Second-order kinetic model } & \multicolumn{3}{|c|}{ Intraparticle diffusion model } \\
\hline & & & $R^{2}$ & $q_{\text {eq, cal }}(\mathrm{mg} / \mathrm{g})$ & $K_{2}\left(\times 10^{-3}\right)(\mathrm{g} / \mathrm{mg} / \mathrm{min})$ & $R^{2}$ & $k_{\mathrm{id}}(\mathrm{mg} / \mathrm{g} / \sqrt{ } \min )$ & $I(\mu \mathrm{g} / \mathrm{g})$ \\
\hline \multirow[t]{2}{*}{ RR 2} & AC-AS & 1836.02 & 0.99 & 1886.79 & 0.00003 & 0.95 & 51.95 & 850.9 \\
\hline & AC-CP & 2130.80 & 0.99 & 2173.91 & 0.00002 & 0.92 & 63.70 & 934.5 \\
\hline \multirow[t]{2}{*}{ RY 145A } & AC-AS & 1358.59 & 0.99 & 1351.35 & 0.00007 & 0.92 & 25.16 & 857.3 \\
\hline & AC-CP & 1626.64 & 0.99 & 1639.34 & 0.00004 & 0.94 & 38.54 & 864.0 \\
\hline
\end{tabular}

Table 3 Adsorption thermodynamic parameters of RR 2 and RY 145A on AC-AS and $\mathrm{AC}-\mathrm{CP}$

\begin{tabular}{|c|c|c|c|c|c|}
\hline Dye & Adsorben & & $\Delta \mathrm{G}^{\circ}(\mathrm{kJ} / \mathrm{mol})$ & $\Delta \mathrm{H}^{\circ}(\mathrm{kJ} / \mathrm{mol})$ & $\Delta \mathrm{S}^{\circ}(\mathrm{kJ} / \mathrm{mol} / \mathrm{K})$ \\
\hline \multirow[t]{6}{*}{ RR 2} & AC-AS & $30^{\circ} \mathrm{C}$ & -7.9 & & \\
\hline & & $45^{\circ} \mathrm{C}$ & -9.2 & 18.48 & 0.087 \\
\hline & & $60^{\circ} \mathrm{C}$ & -10.5 & & \\
\hline & AC-CP & $30^{\circ} \mathrm{C}$ & -9.5 & & \\
\hline & & $45^{\circ} \mathrm{C}$ & -11 & 20.28 & 0.098 \\
\hline & & $60{ }^{\circ} \mathrm{C}$ & -12.5 & & \\
\hline \multirow[t]{6}{*}{ RY 145A } & AC-AS & $30^{\circ} \mathrm{C}$ & -6.6 & & \\
\hline & & $45^{\circ} \mathrm{C}$ & -7.9 & 19.52 & 0.086 \\
\hline & & $60^{\circ} \mathrm{C}$ & -9.2 & & \\
\hline & AC-CP & $30^{\circ} \mathrm{C}$ & -7.3 & & \\
\hline & & $45^{\circ} \mathrm{C}$ & -8.9 & 26.02 & 0.110 \\
\hline & & $60^{\circ} \mathrm{C}$ & -10 & & \\
\hline
\end{tabular}

for RY $145 \mathrm{~A}$, since the process is endothermic and the adsorption capacity of the ACs is less for RY 145A.

\section{Conclusion}

The waste biomass materials used as precursors for the AC synthesis have shown great potential to develop ACs with high surface area. One-step chemical activation using phosphoric acid was successfully carried out, which provides energy saving and becomes more environment friendly, especially when compared to activation by zinc chloride. The dye adsorption values of both the ACs were quite high, and the performance was most comparable with the commercial ACs. The enhanced dye adsorption at higher temperature could be beneficial since cotton dyeing with these reactive dyes is carried out at elevated temperature of about $70{ }^{\circ} \mathrm{C}$ and the effluent temperature reaches nearly $50{ }^{\circ} \mathrm{C}$. Being versatile adsorbent, the applications can be extended for the produced ACs due to their high surface areas.

Acknowledgments This work was supported by the financial assistance under Technical Education Quality Improvement Programme (TEQIP), Phase II, Ministry of Higher and Technical Education, Govt. of Maharashtra, grant number HTED-11029(11)/2/ 2013-MHT-(TE-2), dated November 16, 2013.

\section{List of symbols}

$A_{t}$

$b$

$B_{t}$

$C_{O}$

$C_{t}$

$C_{\text {eq }}$

$\Delta G^{\circ}$

$\Delta H^{\circ}$

$I$

$k_{\mathrm{ad}}$

$k_{\text {id }}$

$k_{L}$

$k_{1}$
Temkin isotherm constant $(\mathrm{L} / \mathrm{g})$

Langmuir adsorption constant $(\mathrm{L} / \mathrm{mg})$

Heat of adsorption $(\mathrm{J} / \mathrm{mol} / \mathrm{K})$

Initial dye concentration $(\mathrm{mg} / \mathrm{L})$

Residual dye concentration at time ' $t$ ' (mg/ L)

Residual dye concentration at equilibrium (mg/L)

Gibbs free energy of adsorption $(\mathrm{kJ} / \mathrm{mol})$

Enthalpy change of adsorption $(\mathrm{kJ} / \mathrm{mol})$

Boundary layer thickness $(\mu \mathrm{g} / \mathrm{g})$

D-R constant related to adsorption energy Intraparticle diffusion rate $(\mathrm{mg} / \mathrm{g} / \sqrt{ } \mathrm{min})$

Adsorption equilibrium constant First-order rate constant (mg/g/min) 
$k_{2} \quad$ Second-order rate constant $(\mathrm{g} / \mathrm{mg} / \mathrm{min})$

$k_{f} \quad$ Freundlich adsorption constant $[(\mathrm{mg} / \mathrm{g})(\mathrm{L} /$ $\mathrm{mg})^{1 / n}$ ]

$n \quad$ Freundlich adsorption constant

$q_{\mathrm{eq}} \quad$ Equilibrium dye uptake $(\mathrm{mg} / \mathrm{g})$

$q_{m} \quad$ D-R maximum sorption capacity $(\mathrm{mg} / \mathrm{g})$

$q_{t} \quad$ Dye uptake at time ' $t$ ' $(\mathrm{mg} / \mathrm{g})$

$Q^{\circ} \quad$ Langmuir adsorption constant $(\mathrm{mg} / \mathrm{g})$

$R \quad$ Universal gas constant $(=8.314 \mathrm{~J} / \mathrm{mol} / \mathrm{K})$

$R^{2} \quad$ Correlation coefficient

$R_{L} \quad$ Langmuir dimensionless separation factor

$\Delta S^{\circ} \quad$ Entropy change of adsorption $(\mathrm{kJ} / \mathrm{mol} / \mathrm{K})$

$t \quad$ Time (min)

$T \quad$ Temperature $\left({ }^{\circ} \mathrm{C}, \mathrm{K}\right)$

\section{References}

Ahmad MA, Paud NAA, Bello OS (2014) Kinetic, equilibrium and thermodynamic studies of synthetic dye removal using pomegranate peel activated carbon prepared by microwave-induced $\mathrm{KOH}$ activation. Resour Ind 6:18-35

Aksu Z, Isoglu IA (2006) Use of agricultural waste sugar beet pulp for the removal of Gemazol turquoise blue-G dye from aqueous solution. J Hazard Mater B317:418-430

Al-Degs YS, Khraisheh MA, Allen SJ, Ahmad MN (2000) Effect of carbon surface chemistry on the removal of reactive dyes from textile effluent. Water Res 34:927-936

Al-Degs YS, El-Barghouthi MI, Khraisheh MA, Ahmad MN, Allen SJ (2004) Effect of surface area, micropores, secondary micropores and mesopores volumes of activated carbons on reactive dyes adsorption from solution. Sep Sci Technol 39:97-111

Al-Degs YS, El-Barghouthi MI, El-Sheikh AH, Walker GM (2008) Effect of solution $\mathrm{pH}$, ionic strength, and temperature on adsorption behavior of reactive dyes on activated carbon. Dyes Pigm 77:16-23

Allègre C, Moulin P, Maisseu M, Charbit M (2006) Treatment and reuse of reactive dyeing effluents. J Membr Sci 269:15-34

Amin NK (2008) Removal of reactive dye from aqueous solutions by adsorption onto activated carbons prepared from sugarcane bagasse pith. Desalination 223:152-161

Auta M, Hameed BH (2011) Optimized waste tea activated carbon for adsorption of methylene blue and acid blue 29 dyes using response surface methodology. Chem Eng J 175:233-243

Bansal RC, Donnet JB, Stoeckli F (1999) A review of active carbon. J Dispersion Sci Technol 11:322-323

Cardoso NF, Lima EC, Pinto IS, Amavisca CV, Royer B, Pinto RB, Alencar WS, Pereira SFP (2011) Application of cupuassu shell as biosorbent for the removal of textile dyes from aqueous solution. J Environ Manage 92:1237-1247
Daud W, Ali W, Suleiman MZ (2000) The effects of carbonization temperature on pore development in palm shell based activated carbon. Carbon 38:1925-1932

Ghaedi M, Karimi F, Barazesh B, Sahraei R, Daneshfar A (2013) Removal of reactive orange 12 from aqueous solutions by adsorption on tin sulfide nanoparticle loaded on activated carbon. J Ind Eng Chem 19:756-763

Girgis BS, Hendawy AN (2002) Porosity development in activated carbons obtained from date pits under chemical activation with phosphoric acid. Microporous Mesoporous Mater 52:105-117

$\mathrm{Hu}$ Z, Srinivasan MP (1999) Preparation of high surface area activated carbons from coconut shell. Microporous Mesoporous Mater 27:11-18

Huang X, Gao N, Zhang Q (2007) Thermodynamics and kinetics of cadmium adsorption onto oxidized granular activated carbon. J Environ Sci 19:1287-1292

Idris MN, Ahmad ZA, Ahmad MA, Ahmad N, Sulaiman SK (2011) Optimization of process variables for malachite green dye removal using rubber seed coat based activated carbon. Int J Eng Technol 11:234-240

Kermit WA, Hong YA, Chung WS, Wayne EM (2006) Select metal adsorption by activated carbon made from peanut shells. Bioresour Technol 97:2266-2270

Kumar PS, Ramalingam S, Senthamarai C, Niranjanaa M, Vijayalakshmi P, Sivanesan S (2010) Adsorption of dye from aqueous solution by cashew nut shell: studies on equilibrium isotherm, kinetics and thermodynamics of interactions. Desalination 261:52-60

La SK, Szu CK (2001) Surface characterization of polyethyleneterphtalate (PET) based activated carbon and the effect of $\mathrm{pH}$ on its adsorption capacity from aqueous phenol and 2,3,4-trichlorophenol solutions. Carbon 39:1945-1953

Mahmoud DK, Salleh MA, Wan WA, Karim A, Idris AA, Abidin ZZ (2012) Batch adsorption of basic dye using acid treated kenaf fiber char: equilibrium, kinetic and thermodynamic studies. Chem Eng J 181-182:449-457

Malik PK (2003) Use of activated carbons prepared from sawdust and rice-husk for adsorption of acid dyes: a case study of acid yellow 36. Dyes Pigm 56:239-249

Namasivayam C, Kavitha D (2002) Removal of congo red from water by adsorption onto activated carbon prepared from coir pith, an agricultural solid waste. Dyes Pigm 54:47-58

Okoye AI, Ijikeme PM, Onukwuli OD (2010) Lead removal from wastewater using fluted pumpkin seed shell activated carbon: adsorption modeling and kinetics. Int $\mathrm{J}$ Environ Sci Technol 7:793-800

Ramakrishnan K, Namasivayam C (2009) Development and characteristics of activated carbons from jatropha husk, an agro industrial solid waste, by chemical activation methods. J Environ Eng Manag 19:173-178

Reddy KSK, Al Shoaibi A, Srinivasakannan C (2015) Preparation of porous carbon from date palm seeds and process optimization. Int J Environ Sci Technol 12:959-966

Reffasa A, Bernardeta V, Davida B, Reinerta L, Lehocineb MB, Duboisc M, Batissec N, Duclauxa L (2010) Carbons prepared from coffee grounds by $\mathrm{H}_{3} \mathrm{PO}_{4}$ activation: characterization and adsorption of methylene blue and nylosan red N-2RBL. J Hazard Mater 175:779-788 
Senthilkumaar S, Varadarajan PR, Porkodi K, Subbhuraam CV (2005) Adsorption of methylene blue onto jute fiber carbon: kinetics and equilibrium studies. $\mathrm{J}$ Colloid Interface Sci 284:78-82

Senthilkumaar S, Kalaamani P, Porkodi K, Varadarajan PR, Subbhuraam CV (2006) Adsorption of dissolved reactive dye from aqueous phase onto activated carbon prepared from agricultural waste. Bioresour Technol 97:1618-1625

Suarez GF, Martinez AA, Tascon J (2002) Pyrolysis of apple pulp: chemical activation with phosphoric acid. J Anal Appl Pyrolysis 63:283-301

Sugumaran P, Susan VP, Ravichandran P, Seshadri S (2012) Production and characterization of activated carbon from banana empty fruit bunch and delonix regia fruit pod. J Sustain Energy Environ 3:125-132

Tsai WT, Chang CY, Lee SL (1997) Preparation and characterization of activated carbons from corn cob. Carbon 35:1198-1200
Vargas AMM, Cazetta AL, Kunita MH, Silva TL, Almeida VC (2011) Adsorption of methylene blue on activated carbon produced from flamboyant pods (Delonix regia): study of adsorption isotherms and kinetic models. Chem Eng $\mathbf{J}$ 168:722-730

Weber WJ, Morris JC (1963) Kinetics of adsorption on carbon from solutions. J Sanit Eng Div 89:31-60

Wu FC, Tseng RI, Jung RS (2001) Kinetic modeling of liquid phase adsorption of reactive dyes and metal ions on chitosan. Water Res 35:613-618

Yennam RA, Pujari M, Uppaluri R (2014) Equilibrium and kinetic studies of $\mathrm{Ni}$ (II) adsorption using pineapple and bamboo stem based adsorbents. Sep Sci Technol 49:533-544 